\title{
Influência da infecção por Covid-19 na funcionalidade da cervical em indivíduos com cefaleia
}

\author{
Lorena Amaral Moreira ${ }^{(D)}$, Ana Maria Moreno Marinho ${ }^{(D)}$, Aretha de Magalhães e Souza ${ }^{\mathbb{D}}$, \\ Camila Rodrigues de Almeida ${ }^{D}$, Juliana Barros Freire ${ }^{(D)}$, Ticiana Mesquita de Oliveira Fontenele ${ }^{(D)}$, \\ Maíra de Oliveira Viana Rela ${ }^{D}$
}

Universidade de Fortaleza, Fortaleza, Ceará, Brasil

\section{Introdução}

Em março de 2020, a Covid-19 foi caracterizada como uma pandemia. O SARS-COV-2 é altamente infeccioso, podendo gerar complicações e sequelas graves. Um de seus sintomas principais é a cefaleia, tendo como característica dor e limitações na mobilidade da cervical.

\section{Objetivo}

Analisar a influência da infecção por Covid-19 na funcionalidade da cervical em indivíduos com cefaleia.

\section{Material e Métodos}

Estudo transversal, quantitativo, realizado no setor de fisioterapia do Núcleo de Atenção Médica Integrada, da Universidade de Fortaleza, no período de maio a agosto de 2021, em indivíduos acima de 18 anos, ambos os gêneros, com diagnostico de cefaleia há pelo menos 6 meses e exclusos os fibromiálgicos, com distúrbios neurológicos e em uso de analgésico. $O$ instrumento de coleta abordou: dados sociodemográficos, características da cefaleia, infecção por Covid-19 e o Neck Disability Index (NDI), específico para avaliar a capacidade funcional cervical. Aprovado com parecer $n^{\circ}$ 4.618.892.

\section{Resultados}

Participaram 37 indivíduos com idade média de $28,95 \pm 12,18$, com predomínio do sexo feminino $(83,8 \%)$ e cefaleia de intensidade moderada, segundo a Escala Visual Analógica. Confirmaram a positividade da Covid-19, 13 indivíduos e destes 11 sentiram dor de cabeça durante a infecção. Segundo o NDI, 25 participantes apresentaram "incapacidade mínima", destes 10 tiveram Covid-19, seguido por 6 indivíduos com "incapacidade moderada". Ao relacionar a infecção por Covid-19 com a capacidade funcional da cervical, verificou-se que não houve associação significante. Porém, ao correlacionar a intensidade da cefaleia e a funcionalidade da cervical observou associação significante $(p<0,01)$. Os dados foram analisados pelo software estatístico SPSS.

\section{Conclusão}

Não obteve relação concreta de que a infecção por Covid-19 prejudicou a funcionalidade da cervical, porém vemos a prevalência da cefaleia durante a infecção. Existe correlação da intensidade da cefaleia com a capacidade funcional da cervical.

Palavras-chave: Covid-19, Cefaleia, Cervical, Funcionalidade. 